\title{
Grisel Syndrome: Case Report
}

\section{Síndrome de Grisel: Relato de caso}

\author{
Bruno Roncaglio ${ }^{1}$ Tadeu Gervazoni Debom¹ Marcus Alexandre Novo Brazolino ${ }^{1}$ \\ Thiago Cardoso Maia ${ }^{1}$ José Lucas Batista Filho ${ }^{1}$ Igor Machado Cardoso ${ }^{1}$ Charbel Jacob Junior ${ }^{1}$ (1) \\ ${ }^{1}$ Department of Orthopedics and Traumatology, Instituto de Coluna
Vertebral, Hospital Santa Casa de Misericórdia, Vitória, ES, Brazil \\ Arq Bras Neurocir 2020;39(1):37-40. \\ Address for correspondence Bruno Roncaglio, Departamento de \\ Ortopedia e Traumatologia, Instituto de Coluna Vertebral, Hospital \\ Santa Casa de Misericórdia, Vítória, ES, 29025-023, Brazil \\ (e-mail: institutodecoluna@gmail.com; brroncaglio@gmail.com).
}

\author{
Abstract \\ Keywords \\ - atlantoaxial joint / \\ injuries \\ - grisel syndrome / \\ treatment
}

We report a case of a rare disease, Grisel syndrome, which manifests as a kind of rotational fixation of the atlas on the axis, resulting from an infectious process of the upper airways. In the present report, we discuss etiology, clinical presentation, diagnosis, treatment and outcome after intervention.

Relatamos um caso de doença rara, a síndrome de Grisel, que se manifesta como um tipo de fixação rotatória do atlas sobre o áxis, decorrente de processo infeccioso das vias aéreas superiores. Neste relato, discutiremos etiologia, quadro clínico, diagnóstico, tratamento e evolução do caso após intervenção.

\section{Introduction}

Grisel syndrome is a rare type of rotational fixation of the atlas on the axis (C1-C2), initially described in 1830, when Bell ${ }^{1}$ reported a case of atlantoaxial subluxation secondary to a process of syphilitic ulcerative pharynx. Subsequently, it has been described as a rare complication of inflammatory processes secondary to otorhinolaryngological and gastroenterologic surgical interventions and to upper airway infections (UAIs). The etiopathogenesis has not been fully clarified, but it is described as an association with an infection or inflammatory process of the head and neck region with subsequent dissemination to the atlantoaxial joint, which would weaken at the level of its bone and ligamentous insertion. It has an incidence of $68 \%$ among the population younger than 12 years of age, and of $90 \%$ among those under 21 years of age. ${ }^{2,3}$ The typical presentation is with cervical pain, deformity and limitation of movements (fixed torticollis), with the existence of a recent inflammatory or infectious process. The child adopts a cock robin position, due to the presence of the socalled paradoxical torticollis, which differs from the common muscular torticollis because, instead of shortening, there is stretching of the sternocleidomastoid muscle. Another finding from the clinical examination is the Sudek sign, in which the C2 spinous process is diverted to the same side of the head. In less than $15 \%$ of the cases, neurological complications occur, ranging from transient sensory alterations to tetraplegia, and even sudden death. The common differential diagnosis is meningitis, and retropharyngeal abscess, spasmodic muscle torticollis, trauma and adverse drug reactions should also be considered. ${ }^{4}$ Imaging exams help in the diagnosis. Radiography and computed tomography (CT) can show an asymmetry between the lateral masses of $\mathrm{C} 1$ and an increase in the atlantodental interval.

The classification of Fielding et $\mathrm{al}^{5}$ ( - Fig. 1) enables the grouping of the different degrees of atlantoaxial subluxation received

September 18, 2017

accepted

December 8, 2017
DOI https://doi.org/

10.1055/s-0037-1598650. ISSN 0103-5355.
Copyright (c) 2020 by Thieme Revinter

Publicações Ltda, Rio de Janeiro, Brazil
License terms

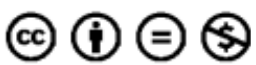




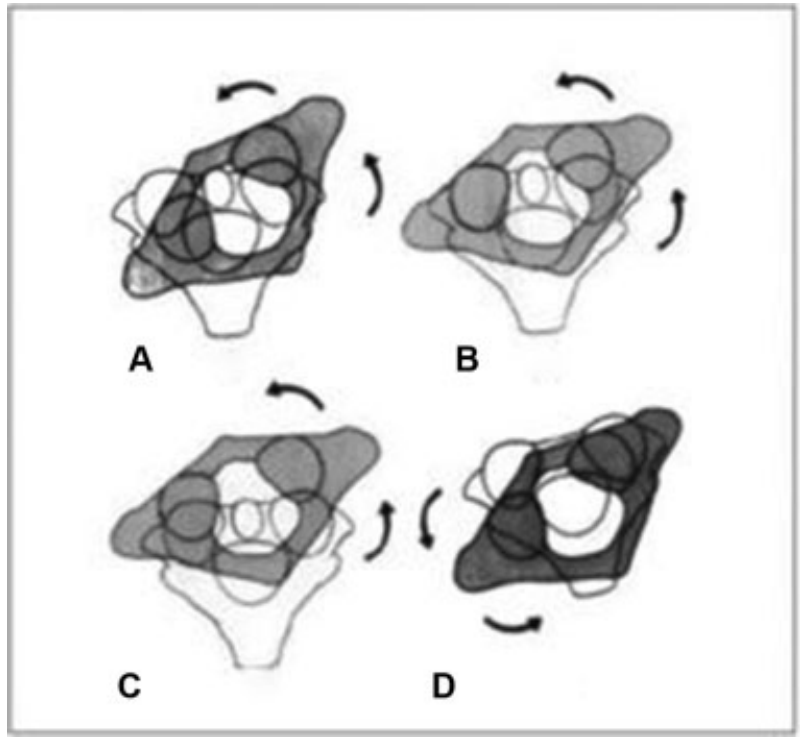

Fig. 1 (A) Type I; (B) type II; (C) type III; (D) type IV.

and assists in the prediction of the prognosis for potential complications, dividing the cases into: type I, fixed rotational subluxation; type II, anterior deviation $=3-5 \mathrm{~mm}$; type III, anterior deviation $>5 \mathrm{~mm}$; and type IV, posterior deviation. The treatment is conservative at first. Cases of failure, irreducible subluxation and recurrences have surgical indication. $^{5}$

The objective of the present work is to report a rare case of Grisel syndrome, with inveterate atlantoaxial subluxation and its treatment with cranial halo, and to describe its physiopathology.

\section{Clinical Case}

A 9-year-old male patient was admitted to our service with cervical pain, deformity and limitation in range of motion for 50 days, with no history of trauma, which was treated as spasmodic torticollis. Regarding his previous history, the patient presented a picture of UAI in the three weeks preceding the onset of symptoms, with resolution after the use of symptomatic relief medications. Upon clinical examination, a limitation in the amplitude of the cervical movement was observed, with inclination of the head to the right and deviation of the contralateral chin, without neurological deficit (-Fig. 2). The patient was submitted to radiography and computed tomography (CT) scans, in which a C1-C2 rotational subluxation was visualized ( $\boldsymbol{- F i g s .} \mathbf{3}, \mathbf{4}$ and $\mathbf{5}$ ). The patient was submitted to cranial halo and traction in a surgical center, which was maintained for 15 days in a Stagnara chair with progressive traction, and subsequently used a halo vest for 12 weeks (-Fig. 6), obtaining C1-C2 reduction with a $5-\mathrm{mm}$ index measured in the coronal and axial planes (-Figs. 7 and 8). The patient presented good evolution with the proposed treatment, and did not evolve with functional limitation in the range of motion of the cervical spine (-Fig. 9).

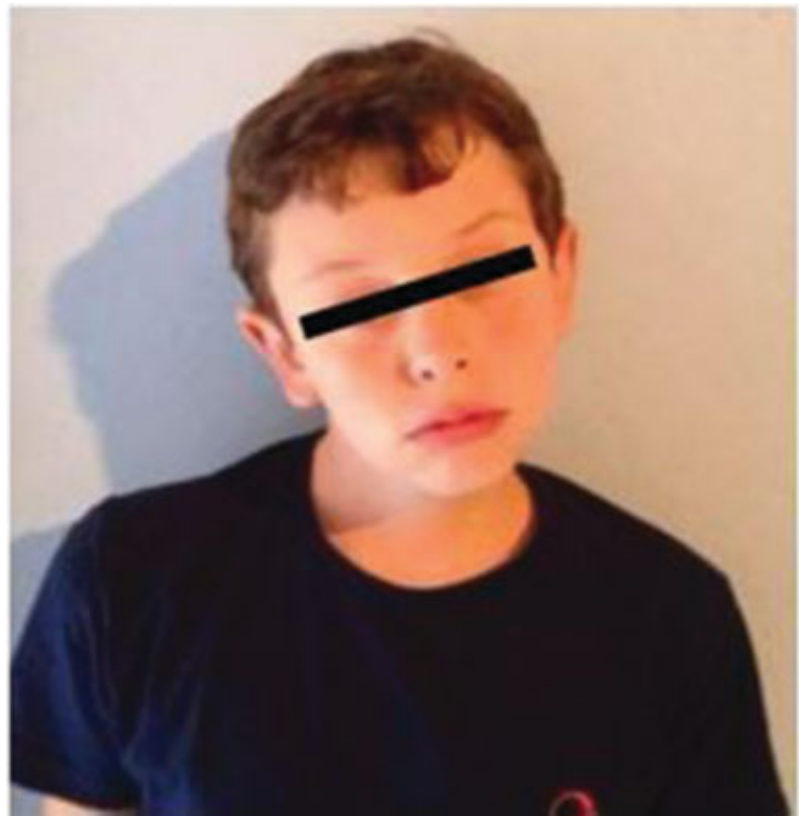

Fig. 2 Clinical image of a patient with head tilt to the right and rotated back to the contralateral side.

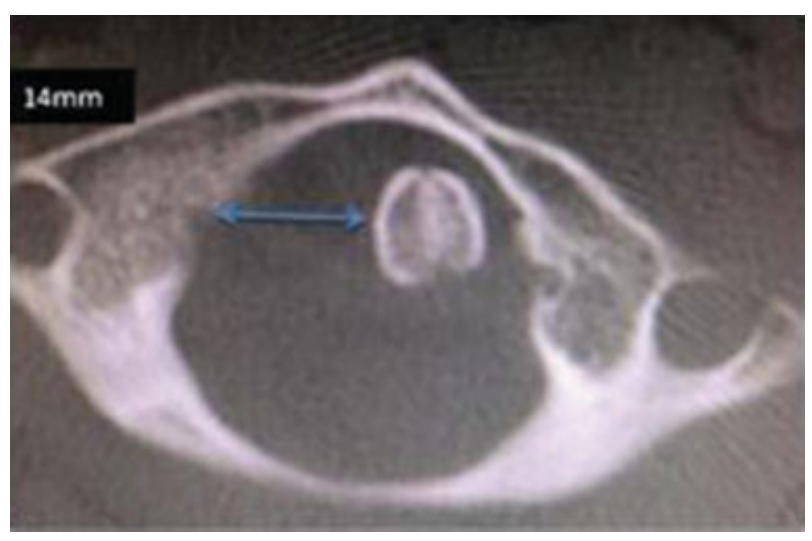

Fig. 3 Computed tomography; axial view showing rotational subluxation in $\mathrm{C} 1-\mathrm{C} 2$.

\section{Discussion}

Grisel syndrome is an eminently pediatric pathology, although there are cases reported in adults. In a series of cases, Watson-Jones ${ }^{6}$ and Wilson et $\mathrm{al}^{4}$ demonstrated that most cases are manifested in children under 10 years old. It results from a pathological relaxation of the ligaments around the C1-C2 joint, following an inflammatory, infectious or surgical procedure. ${ }^{7,8}$

The diagnosis of non-traumatic atlantoaxial subluxation requires radiological investigation. Simple cervical spine radiography may present an asymmetry between the joints in the anteroposterior projection and increase in the atlantodental interval in lateral projections. In children, the atlantodental interval normally measures less than $3 \mathrm{~mm}$. An increase in this interval to more than $5 \mathrm{~mm}$ would suggest traumatic or nontraumatic subluxation. ${ }^{8}$ The exam of choice in the evaluation of the bone cervical spine is the $\mathrm{CT}$, while magnetic resonance 


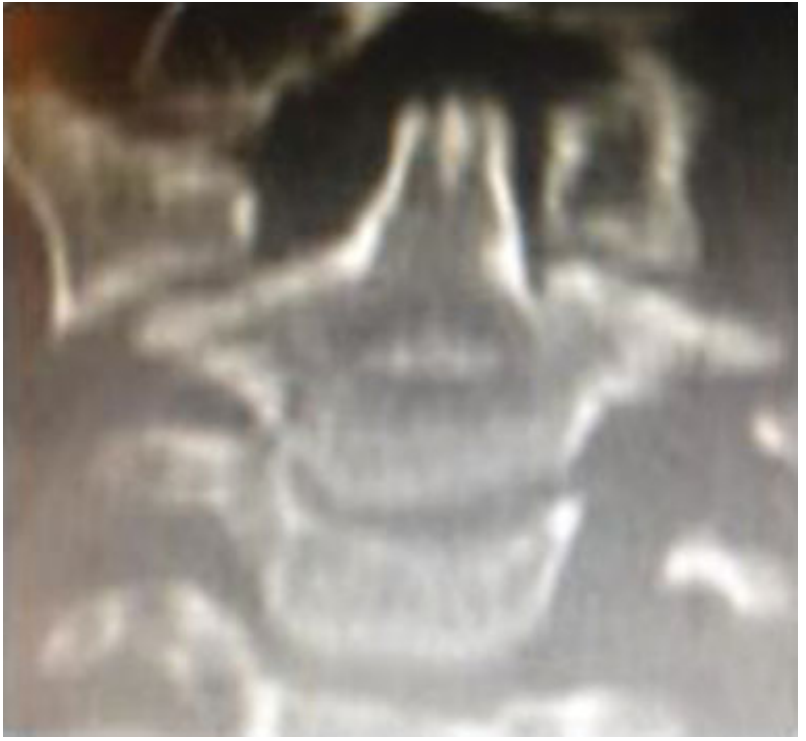

Fig. 4 Computed tomography; coronal view showing rotational subluxation in $\mathrm{C} 1-\mathrm{C} 2$.

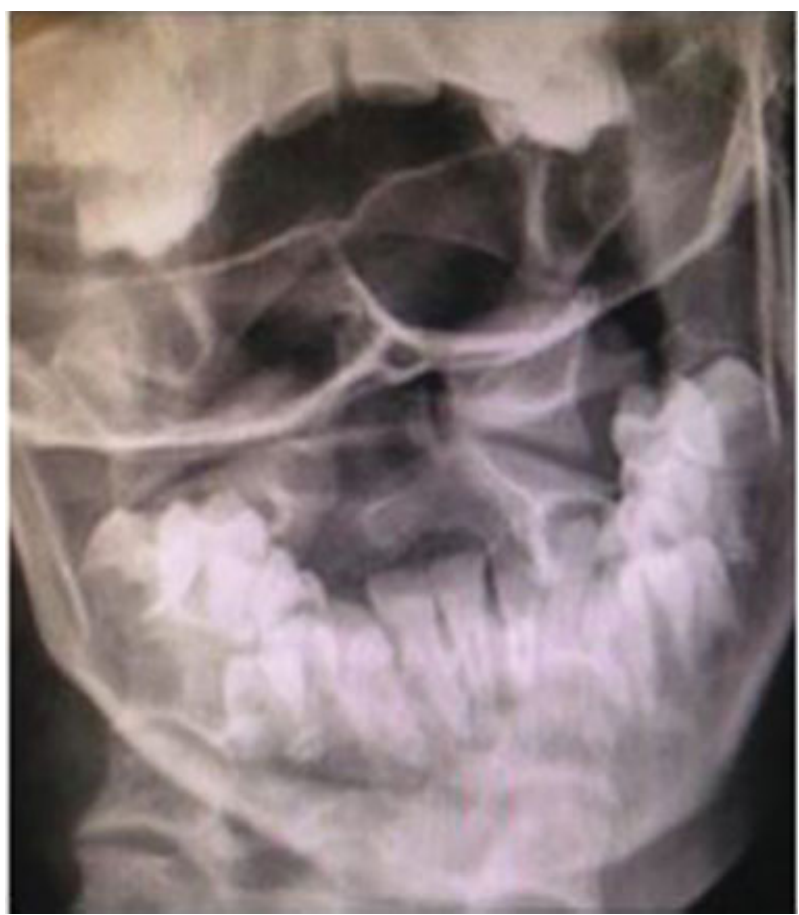

Fig. 5 Transoral radiography of the cervical spine showing subluxation in $\mathrm{C} 1-\mathrm{C} 2$.

imaging (MRI) provides information related to the structures of the surrounding soft tissues and spinal cord.

In the case in question, the patient presented an irreducible lesion, with an atlantoaxial interval of $14 \mathrm{~mm}$, and type III in the Fielding et al ${ }^{5}$ classification. Due to the delayed definitive diagnosis, there was no spontaneous reduction of the subluxation, and the patient was submitted to skeletal traction.

The prognosis with the conservative treatment is excellent, when the diagnosis is established in adequate time, that is, less than 3 weeks after the onset of the first symptoms. After this period, some form of surgical intervention may be required

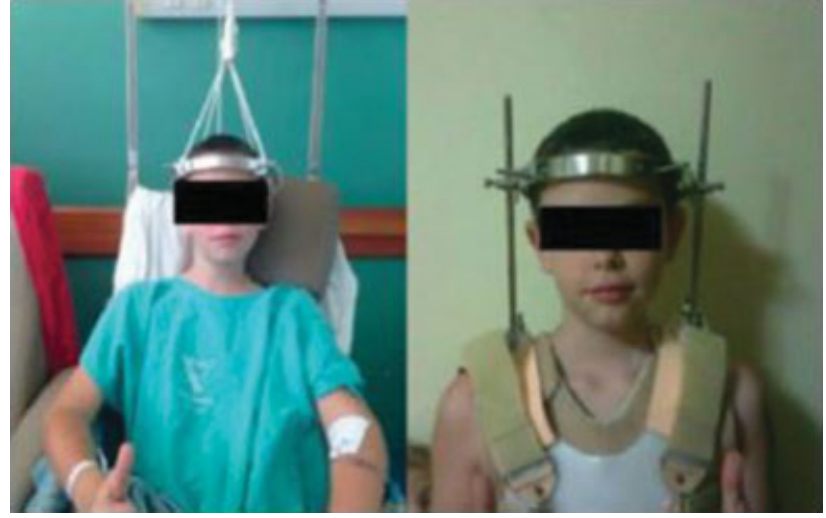

Fig. 6 Patient in traction and with halo vest for bloodless reduction.

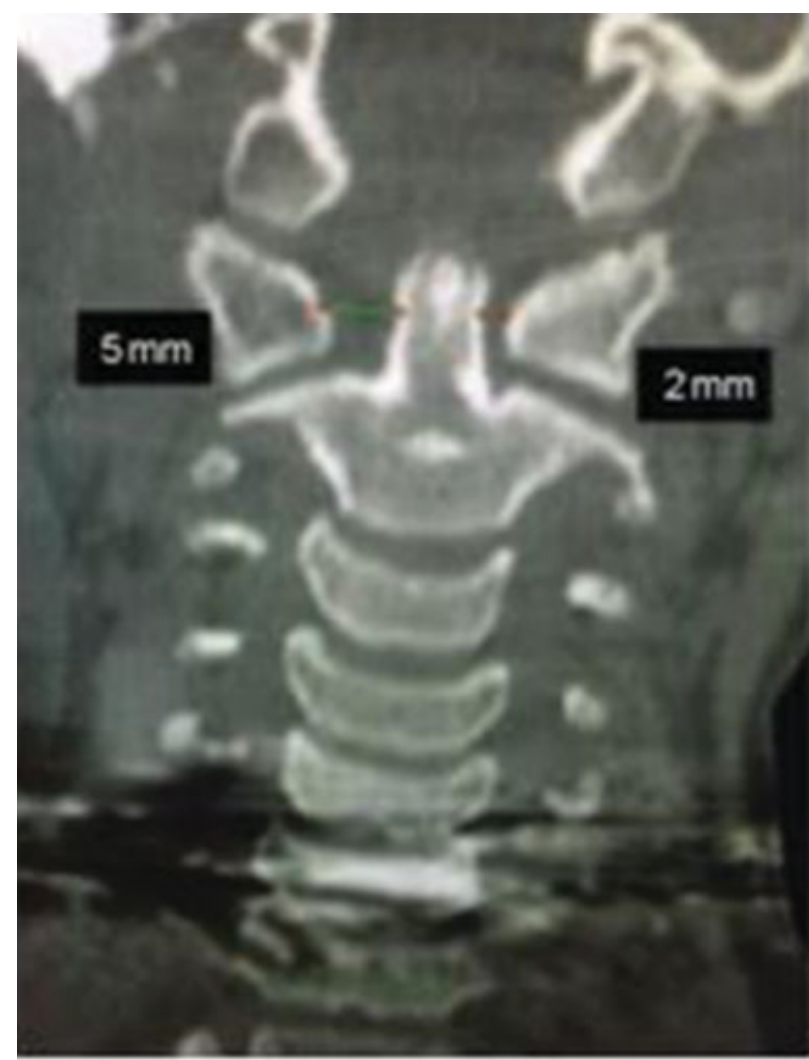

Fig. 7 Computed tomography; frontal view showing acceptable reduction of the subluxation in $\mathrm{C} 1-\mathrm{C} 2$.

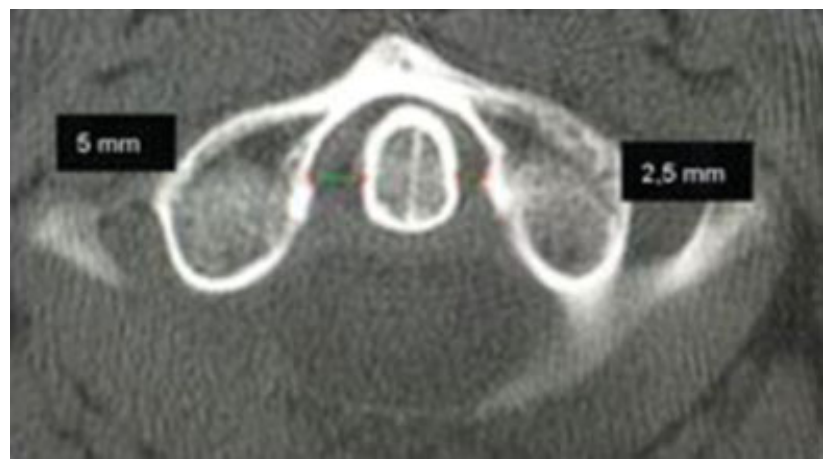

Fig. 8 Computed tomography; axial view showing acceptable reduction of the subluxation in $\mathrm{C} 1-\mathrm{C} 2$. 


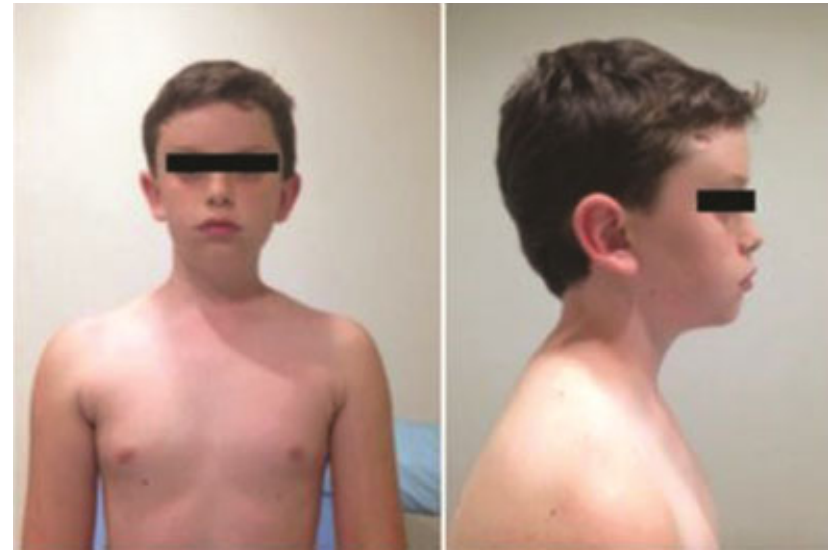

Fig. 9 Clinical image of the patient in anteroposterior and profile views after the reduction.

due to the irreducibility. ${ }^{9}$ In most cases, the subluxation is reduced spontaneously. ${ }^{10}$

The treatment for Grisel syndrome is controversial. It usually starts with conservative and supportive measures, including resting, cervical collar, analgesics, anti-inflammatories, muscle relaxants and, when necessary, antibiotic therapy and abscess drainage. $^{3}$ The expected time for spontaneous reduction, in most cases, is after 7 days of treatment; after the reduction of the lesion and regression of the inflammatory process, the stability is recovered. ${ }^{10}$ In cases in which spontaneous reduction does not occur, manual reduction under sedation, cranial traction and, lastly, surgical treatment with craniocervical arthrodesis may be attempted..$^{9,11,12}$ Wetzel and La Rocca ${ }^{8}$ proposed a treatment protocol for non-traumatic atlantoaxial rotational subluxation based on the Fielding et $\mathrm{al}^{5}$ classification. The conservative treatment for lesions of types I, II and III would be soft paste, rigid collar (Philadelphia) and halo-vest respectively. For type-IV lesions, they recommend surgical treatment, which is also indicated in cases of failure of the conservative treatment, recurrence of subluxation, and irreducible subluxations. $^{8}$ Gomes et $\mathrm{al}^{13}$ evaluated retrospectively 35 cases of Grisel syndrome treated at a referral hospital, and they found 19 female children with a mean age of 6.9 years. Cervical pain was the main complaint of $85 \%$ of the patients, followed by deformity and loss of mobility. History of UAI was present in $80 \%$ of the cases, and trauma was also found in $14 \%$. Only one patient suffered neurological deficit (deltoid and triceps paresis), with complete remission after the treatment. According to Fielding et $\mathrm{al}^{5}{ }^{5} 14$ patients were classified as type II, and there were no cases of type IV. The treatment performed with collar alone in twenty patients had good results. Surgical treatment was performed in six cases, with C1-C2 arthrodesis preceded by a reduction with halo and traction. Complications resulting from the treatment were scarce. Pilge et $\mathrm{al}^{14}$ reported an 11 -year-old patient with 2 months of evolution of atlantoaxial subluxation after surgery for cochlear implantation, in which a reduction was performed under general anesthesia and myorelaxants, followed by cervical collar. The reduction was satisfactory.
The patient in the present report was submitted to progressive load (halo) traction for 2 weeks, and used a halo vest for another 12 weeks. The case showed satisfactory evolution, obtaining a reduction of $\mathrm{C} 1-\mathrm{C} 2$, with an index of around $5 \mathrm{~mm}$ measured in the coronal plane.

\section{Conclusion}

Despite its rarity, it is fundamental that the medical community know this entity, in order to avoid subdiagnoses and consequent irreversible injuries.

\section{Conflict of Interests}

The authors have no conflict of interests to declare.

\section{References}

1 Bell $\mathrm{C}$. The nervous system of the human body, embracing papers to the Royal Society on the subject of nerves. London: Longman, Rees and Orme; 1830:403

2 Bocciolini C, Dall'Olio D, Cunsolo E, Cavazzuti PP, Laudadio P. Grisel's syndrome: a rare complication following adenoidectomy. Acta Otorhinolaryngol Ital 2005;25(04):245-249

3 Fernández Cornejo VJ, Martínez-Lage JF, Piqueras C, Gelabert A, Poza M. Inflammatory atlanto-axial subluxation (Grisel's syndrome) in children: clinical diagnosis and management. Childs Nerv Syst 2003;19(5-6):342-347

4 Wilson M, Michele AA, Jacobson EW. Spontaneous dislocation of the atlanto-axial articulation, including a report of a caso with quadriplegia. J Bone Joint Surg 1940;22:698

5 Fielding JW, Hawkins RJ, Hensinger RN, Francis WR. Atlantoaxial rotary deformities. Orthop Clin North Am 1978;9(04):955-967

6 Watson-Jones R. Spontaneous hyperemic dislocation of the atlas. Proc R Soc Med 1932;25:586

7 Feldmann H, Meister EF, Küttner K. [From the expert's office. Atlanto-axial subluxation with spastic torticollis after adenoidectomy resp. tonsillectomy in rose position - malpractice of the surgeon or the anaesthesiologist?] Laryngorhinootologie 2003;82 (11):799-804

8 Wetzel FT, La Rocca H. Grisel's syndrome. Clin Orthop Relat Res 1989;240(240):141-152

9 Subach BR, McLaughlin MR, Albright AL, Pollack IF. Current management of pediatric atlantoaxial rotatory subluxation. Spine 1998;23(20):2174-2179

10 Phillips WA, Hensinger RN. The management of rotatory atlantoaxial subluxation in children. J Bone Joint Surg Am 1989;71(05): 664-668

11 Martinez-Lage JF, Martinez Perez M, Fernandez Cornejo V, Poza M. Atlanto-axial rotatory subluxation in children: early management. Acta Neurochir (Wien) 2001;143(12):1223-1228

12 Park SW, Cho KH, Shin YS, et al. Successful reduction for a pediatric chronic atlantoaxial rotatory fixation (Grisel syndrome) with long-term halter traction: case report. Spine 2005;30(15): E444-E449

13 Gomes FCP, Meyer GPV, Lutaka AS, et al. Avaliação retrospectiva dos casos de Síndrome de Grisel no IOT-HCFMUSP. Coluna/ Columna vol.10 n.2. São Paulo2011

14 Pilge H, Prodinger PM, Bürklein D, Holzapfel BM, Lauen J. Nontraumatic subluxation of the atlanto-axial joint as rare form of acquired torticollis: diagnosis and clinical features of the Grisel's syndrome. Spine 2011;36(11):E747-E751 